\title{
Acoustic Evaluation of Fishery Resources in Seawater Reservoir and Water-Intake Open Channel of Taishan Nuclear Power Plant
}

\author{
MENG Wei ${ }^{1,2}$, LIU Xiaolin ${ }^{1}$, TANG Yong ${ }^{2}$, WANG Shuai ${ }^{1}$, ZHANG Jinfei ${ }^{1}$ \\ ${ }^{1} \mathrm{Su}$ Zhou Nuclear Power Research Institute, Suzhou 215004, China \\ ${ }^{2}$ Dalian Ocean University, College of Marine Sciences, Dalian116021, China
}

\begin{abstract}
The CGN Taishan NPP seawater storage is a land-sealed type and is connected to the open water intake channel of Dajin Island in the open sea through a subsea tunnel. Due to the impact of large-scale facility aquaculture in the nearby seas, fish spawning grounds have been formed in this area, and fish breeds faster. A large number of fish have impacted on safe operation of nuclear power. In response to this situation, this study conducted acoustic navigation surveys of fish resources in most waters of the "Sea Reservoir" and "Water intake channel", using broadband scientific fish finder system (EK80, 120kHz, $200 \mathrm{kHz}$ ) produced by Norwegian Simrad Company. Evaluation of acoustic resources using echo integration method. The survey scope of seawater storage in this survey is from the entrance to the first barrier (around a distance of $760 \mathrm{~m}$ ) and from the first barrier to a second barrier (around a distance of $220 \mathrm{~m}$ ); the survey distance of the water intake channel is about $1460 \mathrm{~m}$. From the echo image, it can be found that the zooplankton in the sea reservoir is much smaller than the water intake channel, and the fish size of the water intake channel is much larger than that of the sea channel.Acoustic data was processed and analyzed using Echoview software to calculate the average SV and detect the strength of the single target. The results show that in the survey area of the Taishan Nuclear Power Plant Hai Reservoir, the total number of fish is about 1.38 million, the total weight is about 13.6 tons, and the fish with a body length of less than $20 \mathrm{~cm}$ is the majority, and there are fewer large-sized fish; The total resources in the survey area is about 47 tons, with a total number of 27 million, and has a high density.
\end{abstract}

\section{Introduction}

The reservoir of CGNPC Taishan Nuclear Power Plant is a land closed-type reservoir connected to water-intake open channel on Dajin Island in open seas via subsea tunnel (Fig.1). Impacted by large-scale breeding industry in surrounding waters, a good fish spawning ground is formed in this area with fast fish reproduction. Both the seawater reservoir and water-intake open channel have been found with many fish species, which exert an influence on safe nuclear power operation ${ }^{[1]}$.

Acoustic investigation and evaluation method of fishery resources has been more and more extensively applied to fields like fishery resource evaluation and ecoenvironmental investigation by virtue of high efficiency and convenient comparative analysis not needing any contact, and moreover, it does not damage fishery resources and echo image data can be saved and played back $^{[2]}$, and it has become an important ecological monitoring means both home and abroad ${ }^{[3-6]}$. Relevant domestic researches started in 1913. With increasing fundamental acoustic researches on the fishery industry and promotion of practical application technologies in recent years, this method has been widely applied to fishery resource investigation and evaluation of the Yellow Sea, the East Sea and the South China Sea as well as main inland rivers like the Yangtze River and the Pearl River,and also lakes and reservoirs, and outstanding effects have been achieved ${ }^{[7-13]}$. Therefore, a fishery resource investigation was carried out this time for most water areas (areas marked with design courses) in "seawater reservoir" and "water-intake open channel" (note: water area before coarse screen of seawater reservoir is a safety restricted area, and the first half part of water-intake open channel is a sea area in construction). As the nuclear power plant was in shortage of necessary sampling netting gears, acoustic vessel-mounted method was adopted in this investigation and resource evaluation was implemented using echo integral method ${ }^{[14]}$.

\footnotetext{
$\overline{\text { *MENG Wei: mengwei@cgnpc.com.cn }}$
} 


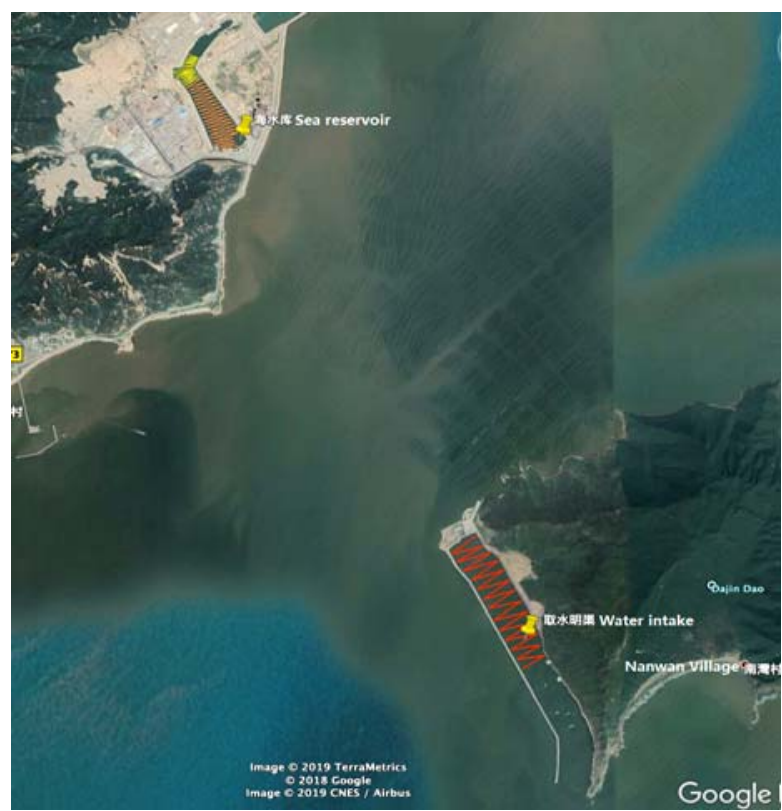

Fig.1 Acoustic design drawing of seawater storage (top) and water intake channel (bottom) at Taishan nuclear power plant

\section{Investigation materials and methods}

Broadband scientific fish finder system produced by Norwegian Simrad Corporation (EK80, 120 kHz, 200 $\mathrm{kHz}$ ) was used in this investigation to collect fish echo data, and position data were received by GPA, which was produced by Garmin, synchronously with the scientific fish finder system through RS232 serial port. Vessel-mounted sampling method was adopted to collect acoustic data, and the course was designed as a triangle as seen in Fig.1 (course-free area was unsampled area in this investigation), where the cross-course design interval for sampling in the seawater reservoir was $35 \mathrm{~m}$ and that in the water-intake open channel was $100 \mathrm{~m}$ (Fig.1). The investigation date of the seawater reservoir was June 18, 2019 and that of the water-intake open channel was June 19.

DC12V storage battery was used to supply power which was transformed into $\mathrm{AC} 220 \mathrm{~V}$ output via inverter and then supplied to the scientific fish finder, network switch and data acquisition PC.The purpose-made special stand was used to fix the transducer at ship' s rail with draught of $50 \mathrm{~cm}$. The investigation ship was a small sunshade-free boat with fiberglass reinforced plastic structure and tail diesel engine, it was about $6 \mathrm{~m}$ in length, and the diesel engine was of 6 horsepower. Fig. 2 displays field working pictures. Data processing was implemented using Australian Echoview software.

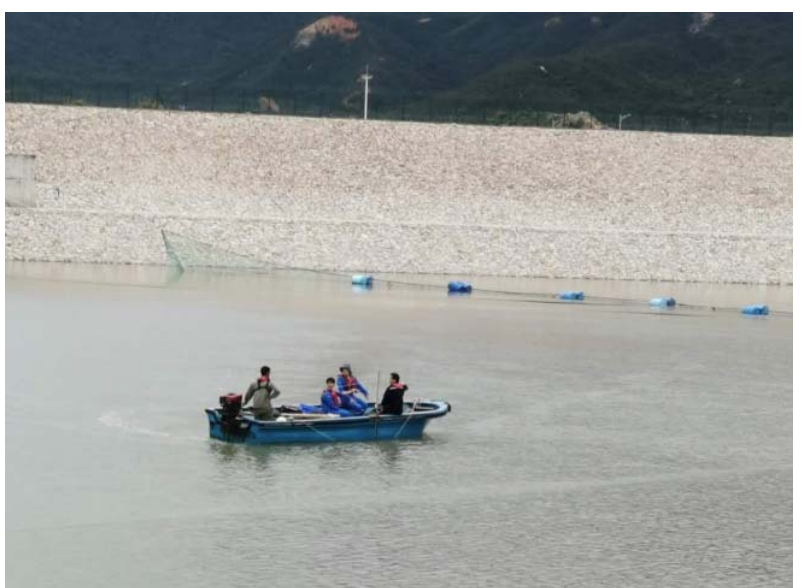

Fig.2 Acoustic survey of seawater storage in Taishan nuclear power plant

\section{Investigation results}

\subsection{Investigation map}

Actual investigation track lines and statistical areas of the seawater reservoir and water-intake open channel are shown in Fig. 3 and Fig.4. The purple part is $2 \mathrm{~m}$ water depth part at the edge of the seawater reservoir and the green part is current bubble area at its entrance. The distance from entrance of the seawater reservoir to the first intercepting net was about $760 \mathrm{~m}$ and that from the first intercepting net to the second one was $220 \mathrm{~m}$ or so. The investigation distance of the water-intake open channel was about $1,460 \mathrm{~m}$. The statistical areas extended from the south to north, the seawater reservoir was divided into 4 areas (Fig.3), where intercepting nets existed between area 4 and areas 1-3. The water-intake open channel was divided into 3 areas from the south to north (Fig.4).

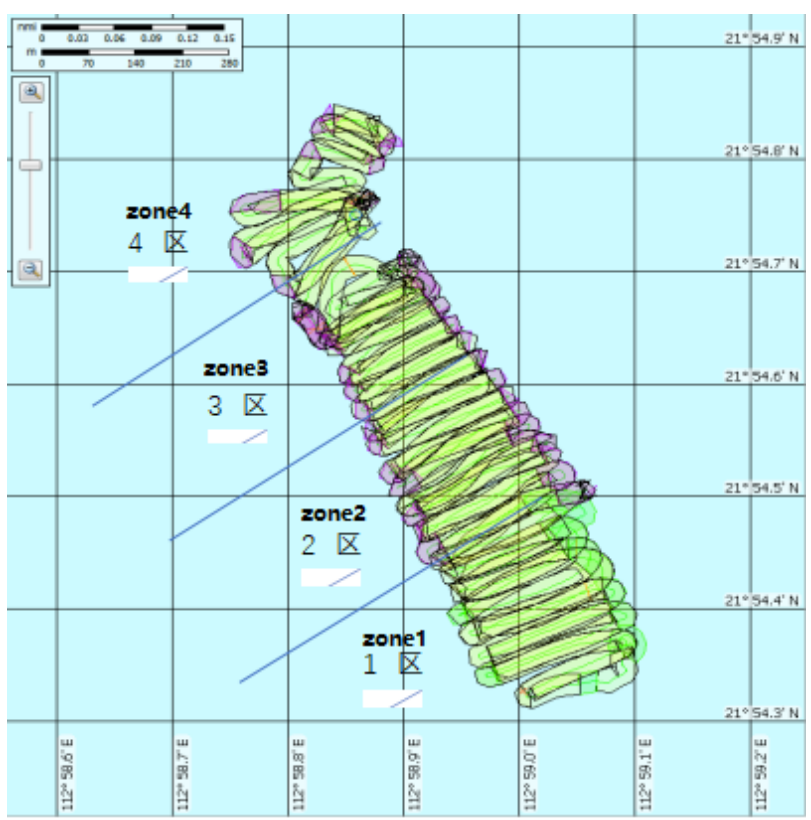


Fig.3 Acoustic survey track and statistical partition of fish stocks in seawater storage at Taishan nuclear power plant

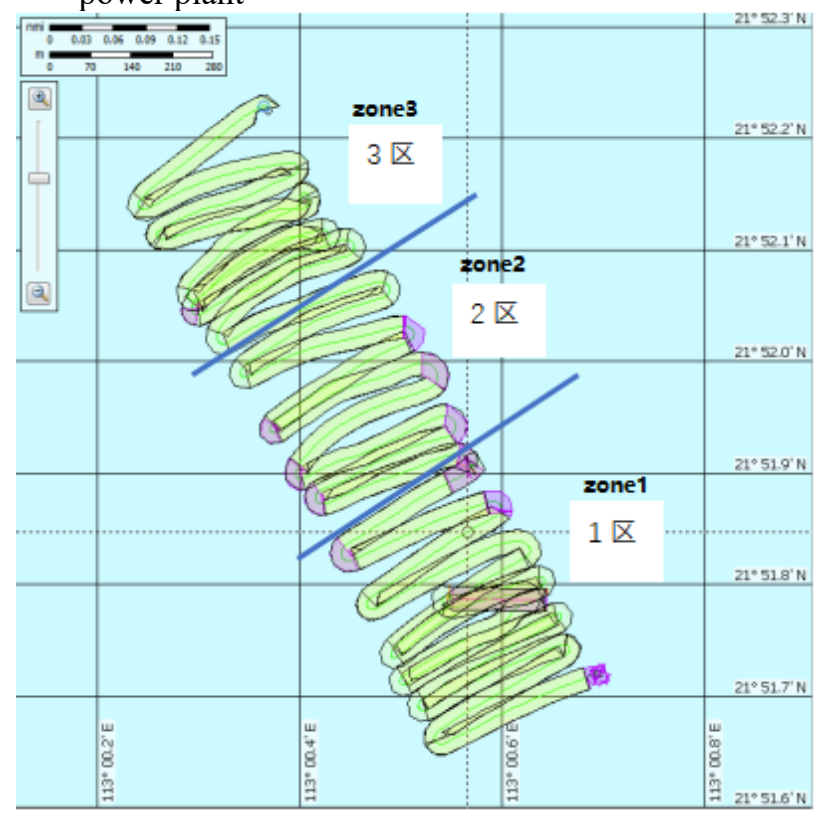

Fig.4 Acoustic survey track of fish stocks in water intake channel at Taishan nuclear power plant

\subsection{Fish echo images}

The echo images of investigation courses in the seawater reservoir and water-intake open channel are shown in Fig.5, where red band represents seabed echo, red plaque-shaped echo is small-sized fish school echo, and what is dispersive is target echo of monomer fish. Individual target echo intensity is in direct proportion to fish body length, so is echo intensity of fish school to school density. By comparing the echoes of the seawater reservoir and water-intake open channel, zooplanktons in the seawater reservoir were much smaller than those in the water-intake open channel, and fish specifications in the water-intake open channel are much larger than those in the seawater reservoir.

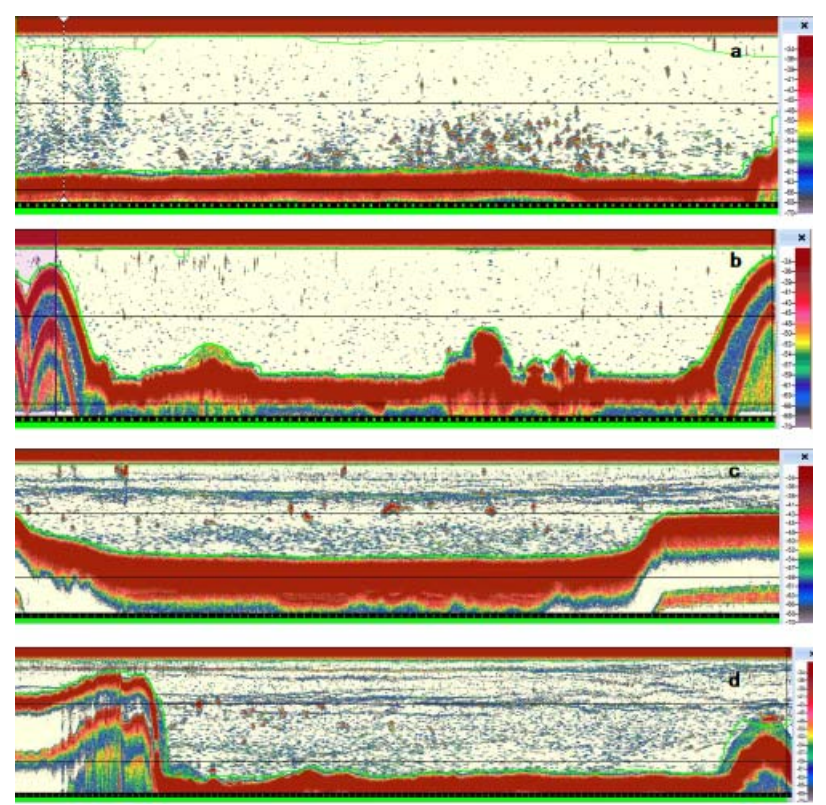

Fig.5 The features of fish echo distribution in different areas:

(a) dense fish school near the seabed in seawater storage area 1 ;

(b) small size single fish in seawater storage area 4, water depth about $8 \mathrm{~m}$;

(c) fish school (red) in water intake channel 1, water depth about $8 \mathrm{~m}$;

(d) single target in 5-6m water layer on the last course in water intake channel 3, water depth is about 12 meters, span is about $300 \mathrm{~m}$

\subsection{Backward acoustic volume scattering intensity of fish (SV) in different areas of the investigated waters}

The acoustic echo data of each course were processed, and the echoes of sea surface, seabed and other nonwater bodies were excluded to calculate average backward target volume scattering intensity (SV) of each course, and the results are shown in Fig.6, where the starting point is water inlet of the seawater reservoir and the end point is intercepting net in the waters outside coarse screen of the power plant, and different distance intervals (areas1-4) between the two places are corresponding to average acoustic reflection coefficient (SV) of fish schools investigated in each course, and this value represents the overall quantity of fish resources. $\mathrm{SV}$ value in area 3 is the maximum while that in area 4 is the minimum. Fig.7 shows average SVs in different areas of the water-intake open channel, where average $\mathrm{SV}$ in area 1 is the highest and those in areas 2 and 3 are relatively low.

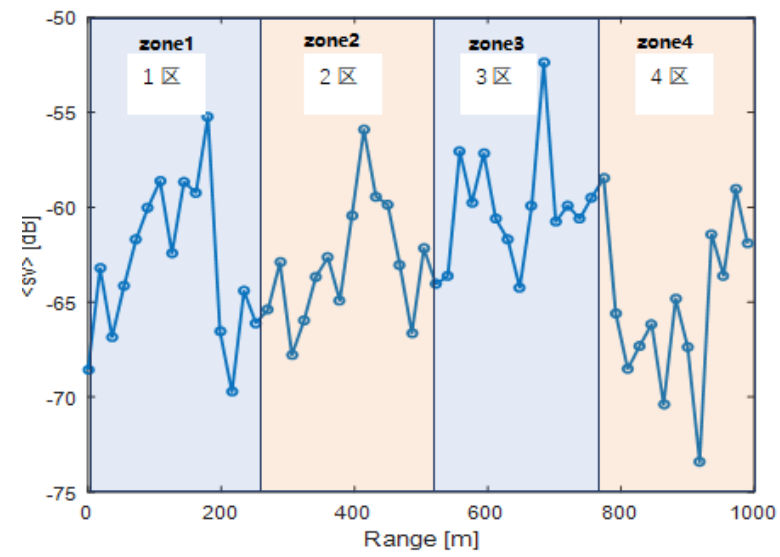

Fig.6 Average Sv of fish in different regions in seawater storage 


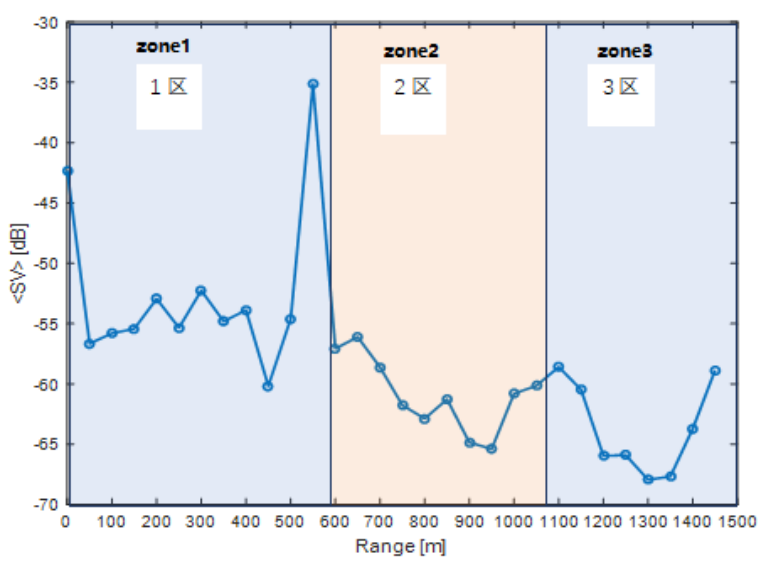

Fig.7 Average Sv of fish in different regions in water intake channel

\subsection{Aqueous layer distribution of fish species of different specifications in different areas of the seawater reservoir}

Aqueous layer (depth) distribution of individual target fish with body length exceeding $5 \mathrm{~cm}$ in the seawater reservoir was carried out. The conversion formula between fish target strength (TS) and fish body length refers to formula 1 in section 3.5. The results of areas 14 are displayed in Fig.8-11, where y-coordinate is water depth, and $\mathrm{x}$-coordinate denotes fish target strength (convertible with body length).

Fish targets with body length ranging from $5 \mathrm{~cm}$ (TS: $-50 \mathrm{~dB}$ ) to $17 \mathrm{~cm}$ (TS: $-41 \mathrm{~dB}$ ) in area 1 were mainly distributed within the interval of $6 \mathrm{~m}-9 \mathrm{~m}$; that in area 2 was $5 \mathrm{~m}-9 \mathrm{~m}$; that in area 3 was $6 \mathrm{~m}-9 \mathrm{~m}$; that in area 4 was $7 \mathrm{~m}-9 \mathrm{~m}$, where the number of aqueous layers where the fish targets were located was small. The aqueous layer distribution of large-size fish in area 1 was relatively uniform; They were distributed at two aqueous layers in area 2, namely $5 \mathrm{~m}$ and $8 \mathrm{~m}$ aqueous layers; They were mostly distributed at $6 \mathrm{~m}$ depth in area 3 ; They were distributed only at about $8 \mathrm{~m}$ depth in area 4.

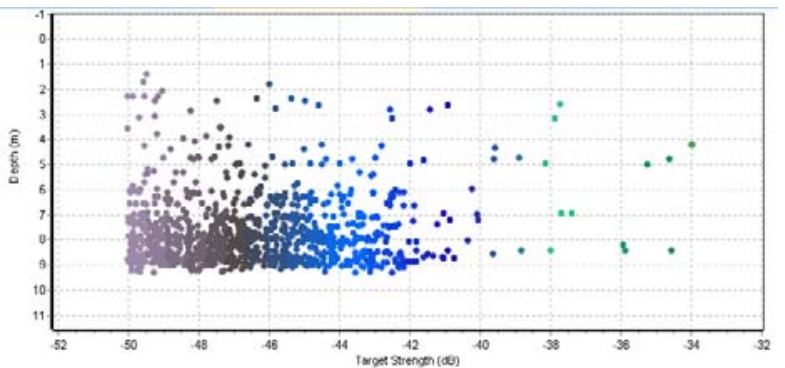

Fig.8 Vertical distribution of fish of different sizes in seawater storage 1

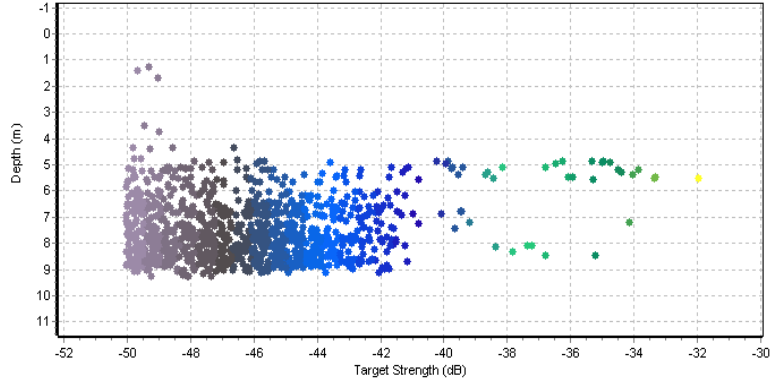

Fig.9 Vertical distribution of fish of different sizes in seawater storage 2

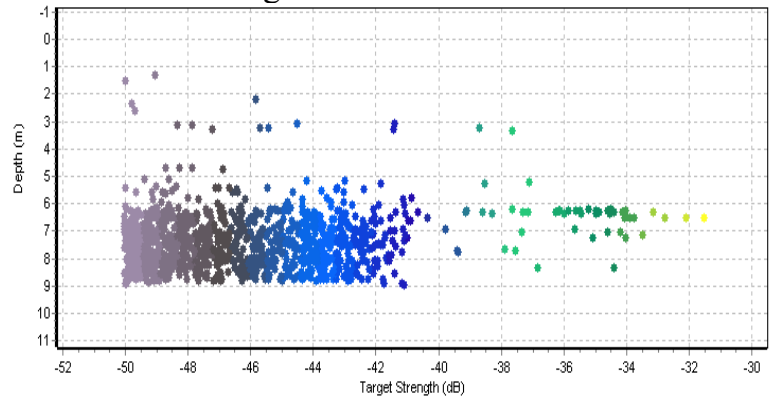

Fig.10 Vertical distribution of fish of different sizes in seawater storage 3

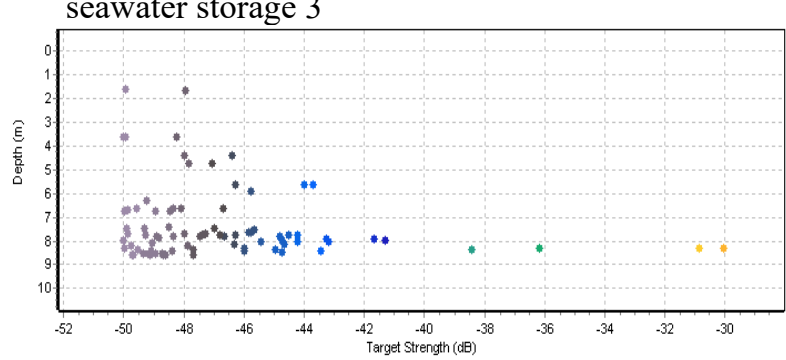

Fig.11 Vertical distribution of fish of different sizes in seawater storage 4

\subsection{Density and quantity of fish resources}

According to the distribution of individual target strength (TS), average body length Lcm of fish within different specification intervals is derived;

$$
\mathrm{TS}=20 \log \mathrm{Lcm}-66
$$

The average density of fish within different specification intervals is calculated via echo integral method; The body length/body weight conversion relational model of millet is used as below,

$$
\mathrm{W}_{\mathrm{g}}=1,2716 \times 10^{-5} \mathrm{~L}_{\mathrm{cm}}{ }^{3.0695}
$$

Where unit of body weight wg is g and that of body length $\mathrm{Lcm}$ is $\mathrm{cm}$. The average weight corresponding to average body length within different specification intervals is deduced, and total weight (resource quantity) is the product of average density with the area and average weight.

The investigation results are presented as follows:

(1) Investigation results of the seawater reservoir 
In the investigated area of the seawater reservoir in Taishan Nuclear Power Plant, the density and weight of fish of different specifications in different intervals are seen in Tab.1, where total quantity is about 1,380,000 and total weight is about $13.6 \mathrm{t}$. The investigation results of the seawater reservoir are: fish with body length being smaller than $20 \mathrm{~cm}$ account for the vast majority, and there are few fish of large specifications, and the quantity of fish with body length exceeding $40 \mathrm{~cm}$ is about 1,400 .

Tab.1 Fish resources in different regions in seawater storage at Taishan nuclear power plant

\begin{tabular}{|c|c|c|c|c|c|c|c|}
\hline Partition & 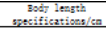 & $<10$ & $10<L<20$ & $20<L<30$ & $30<L<40$ & $>40$ & Total \\
\hline \multirow[t]{2}{*}{$1_{\text {Area }}$} & Teight $/ t$ & 0.68 & 1.09 & 0.18 & 0.24 & 0.28 & 2.48 \\
\hline & Quantity/tail & 378493 & 31092 & 856 & 389 & 156 & 410984 \\
\hline \multirow[t]{2}{*}{2 Area } & $\pi_{\text {eight }} / \mathrm{t}$ & 0.54 & 1.06 & 0.24 & 0.61 & 0.44 & 2.88 \\
\hline & Quantity/tail & 316723 & 29435 & 1167 & 1037 & 259 & 348623 \\
\hline \multirow[t]{2}{*}{3 Area } & Weight $/ t$ & 0.81 & 1.77 & 0.39 & 1.75 & 1.27 & 5.99 \\
\hline & Quantity / tail & 455469 & 45393 & 1849 & 2876 & 719 & 506305 \\
\hline \multirow[t]{2}{*}{4 Area } & Teight $/ t$ & 0.15 & 0.12 & 0.04 & 0.11 & 1.87 & 2.29 \\
\hline & Quantity/tail & 111600 & 4038 & 184 & 184 & 367 & 116372 \\
\hline
\end{tabular}

(2) Investigation results of the water-intake open channel

The resource quantity in the water-intake open channel is seen in Tab.2. The total resource quantity in this investigated area is about $47 \mathrm{t}$ and total quantity is 27 million.

Tab.2 Fish resources in different regions in water intake channel at Taishan nuclear power plant

\begin{tabular}{|c|c|c|c|c|c|c|c|}
\hline Partition & 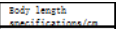 & $\angle 10$ & $10<L<20$ & $20<L<30$ & $30<L<40$ & $>40$ & Total \\
\hline \multirow[t]{2}{*}{ 1 Area } & \begin{tabular}{|l|} 
Wei ght. $/ \mathrm{t}$ \\
\end{tabular} & 8.12 & 10.32 & 10.62 & 4.94 & 0.00 & 34.00 \\
\hline & Quantity/tail & 16042608 & 251223 & 50245 & 8104 & 0 & 16352179 \\
\hline \multirow[t]{2}{*}{2 Area } & Weight/t & 1.84 & 1.59 & 0.98 & 1.41 & 0.00 & 5.83 \\
\hline & Quantity/tail & 6129960 & 39433 & 4639 & 2320 & 0 & 6176353 \\
\hline \multirow[t]{2}{*}{3 Area } & Weight/t & 1.78 & 1.03 & 0.29 & 1.68 & 2.42 & 7.19 \\
\hline & Quantity/tail & 5140621 & 32970 & 1374 & 2748 & 1374 & 5179087 \\
\hline
\end{tabular}

\section{Result analysis}

As the investigation boat used this time was made of fiberglass and tail-hanging diesel engine was used to supply power, large vibration noise would be generated, and at the bottom of the seawater reservoir were hard stones, intimidating effect was then formed on large-size fish, fish would then escape, and the quantity of probed large-size fish would be partially small. Hence, electric impetus generating small noise is recommended.

As the boat was forbidden to get close to the gate of the seawater reservoir, acoustic sampling was insufficient in this area, and then the calculated resource quantity was also partially small. The flow velocity was high nearby the gate entrance in the seawater reservoir with many bubbles, which formed a great impact on acoustic sounding. A measurement dead zone was formed in this area, which could influence the evaluation accuracy to a certain degree.

\section{Acknowledgement}

This work is supported by National Key R\&D Program of China (2017YFC1404400-Subject 4 and 6) ; National Natural Science Foundation of China (61503054).

\section{References}

1. Ruan G P. Cause analysis and countermeasures for water intake blocking in nuclear power plant [J]. Nuclear Power Engineering, 2015,36(S1):151-154.

2. Li B, Li P J, Tang Y, Sun J F, Hu Y D, Zhang J B. Acoustic evaluation of fishery resources in main channel area of Xiaolangdi Reservoir in the Yellow River [J]. Journal of Fisheries of China, 2015,39(08):1134-1143.

3. Koslow J A.The role of acoustics in ecosystembased fishery management [J].Ices Journal of Marine Science,2009,66(6):966-973.

4. Davision P C,Koslow J A,Kloser R J.Acoustic biomass estimation of mesopelagic fish:backscattering from individuals,populations, and communities[J].ICES Journal of Marine Science,2015,72(5):1413-1424.

5. Davision P,Lara-Lopez A,Koslow J A.Mesopelagic fish biomass in the southern California current ecosystem[J].Deep Sea Research Part II:Topical Studies in Oceanography,2015,112:129-142.

6. Zhang J C, Li X S, Zhao X Y, Ying Y P. Schooling morphology and spatial-temporal distribution characteristics of small-size pelagic fishes in central sea area of the Atlantic Ocean in the Middle East [J]. Marine Fisheries, 2017,39(06):601-610.

7. Li N N, Chen G B, Yu J, Li Y Z, Tang Y, Chen P M, Jia X P. Acoustic evaluation of biological resources in artificial fish reef area in Yangmeikeng of Daya Bay $[\mathrm{J}]$. Journal of Fisheries of China, 2011,35(11):1640-1649.

8. Chen G B, Li Y Z, Zhao X Y, Chen Y Z, Jin X S. Acoustic resource evaluation of five significant commercial fishes in the South China Sea [J]. Acta of Oceanologica Sinica (Chinese version), 2006(02):128-134.

9. Chen G B, Li N N, Chen P M, Li Y Z, Yu J, Li X G. Target strength measurement of Siganus oramin in the South China Sea [J]. Journal of Fishery Sciences of China, 2010,17(06):1293-1299.

10. Tan X C, Li X H, Lin J Z, Zhou D H, Gao X, Li J M. Differences of two Megalobrama hoffmanni spawning populations in reproduction ecology based on hydroacoustic sounding [J]. Acta Ecologica Sinica, 2009,29(04):1756-1762.

11. Tao J P. Hydroacoustic study of spatial fish distribution during construction of the Three Gorges Reservoir [C]. Chinese Hydraulic Engineering Society (CHES). Collected papers of 2008 academic annual conference of CHES (volume I). CHES: CHES, 2008:362-371.

12. Huang S, Li L X, Dao W, Li X. Spatial fish distribution feature analysis and resource evaluation in Lugu Lake [J]. South China Fisheries Science, 2020,16(01):53-61.

13. Mo W J, Wang C F, Qin X H, Zhang M J, Liu H J. Hydroacoustics investigation of fish resources in Dongqing and Guangzhao reservoirs areas in Beipan 
River [J]. Journal of Hydroecology, 2015,36(03):1017.

14. Wang J, Zhang C, Wang D, Lin D Q, Li N N, Tang Y. Acoustic evaluation of Aristichthys nobilis in Qinghe reservoir - a comparison of echo counting and echo integral method [J]. South China Fisheries Science, 2010,6(05):50-55. 